\title{
Effectiveness, Safety and Tolerability of Combination of Amlodipine and Valsartan in Hypertensive Patients
}

\author{
Mohammad Nazrul Islam ${ }^{1}$, M. A. Hasanat ${ }^{2}$, Md. Nabiul Hassan Rana ${ }^{3}$, Md. Toufiqur Rahman ${ }^{4}$, \\ Kaisar Nasrullah Khan ${ }^{5}$, Tanvir Mobarak Ali ${ }^{6}$, Md. Mahfuzur Rahman ${ }^{6}$ \\ ${ }^{1}$ Department of Cardiology, Bangabandhu Sheikh Mujib Medical University, Dhaka, ${ }^{2}$ Department of \\ Endocrinology, Bangabandhu Sheikh Mujib Medical University, Dhaka, ${ }^{3}$ Department of Nephrology, \\ Apollo Hospital, Dhaka, ${ }^{4}$ Department of Cardiology, National Institute of Cardiovascular Diseases, Dhaka, \\ ${ }^{5}$ Department of Cardiology, United Hospital Ltd., Dhaka, ${ }^{6}$ Novartis (Bangladesh) Limited, Dhaka
}

Key Words : Amlodipine, valsartan, arterial hypertension, monotherapy.

\begin{abstract}
:
Background: Hypertension is a major public health challenge worldwide and majority of patients fail to achieve blood pressure control with monotherapy. The purpose of the present study was to assess effectiveness of single pill combination of amlodipine and valsartan as anti-hypertensive therapy under real life conditions.
\end{abstract}

Methods: This prospective, non-interventional, open-label, non-comparative observational, multicenter study was conducted from July 2013 to October 2014. This study was carried out among the hypertensive patients who were treated with single pill of amlodinpine and valsartan. Data were collected at baseline and end of study time points. The study was considered as completed for an individual patient when the treatment was completed approximately $26 \pm 8$ weeks. The assignment of the patient to the therapy was decided within the current practice and the medical indication, and was clearly separated from the decision to include the patient in the study.

Results: The study enrolled 278 patients. Of these 236(84.9\%) patients completed the study. Nonserious adverse events were reported in 19(6.8\%) cases. During enrollment of the study majority patients were in the more than $140 \mathrm{mmHg}$ systolic BP group which was 205(73.7\%) patients which was gradually decreased to 101(36.3\%) and 59(21.2\%) at 2nd and final visit respectively $(p=<0.05)$. The proportion of patients in the group of more than $90 \mathrm{mmHg}$ diastolic BP was gradually decreasing from baseline to the final visit during the single pill combination of amlodinpine/valsartan which was 95(34.2\%) during enrollment followed by 42(15.1\%) and 33(11.9\%) patients in 2nd visit and final visit respectively. Considering the diabetes mellitus (DM) patients the high SBP was gradually decreased from $74(77.9 \%)$ to $50(52.6 \%)$ patients during enrollment and final visit respectively. Again in DM patients the high DBP (>80 $\mathrm{mmHg}$ ) was gradually decreased from $61(64.2 \%)$ patients to $29(30.5 \%)$ patients during enrollment and final visit respectively.

Conclusion: The single pill combination of amlodipine/valsartan is significantly reduced the blood pressure among the hypertensive patients in real world settings.

(Cardiovasc.j. 2016; 9(1): 13-18)

\section{Introduction:}

Hypertension is the world's number one cause of death. It is the main cause for cardiovascular (CV) diseases..$^{1}$ In addition to that the complications and comorbidities associated with hypertensions include cerebrovascular disease, ischemic heart disease, cardiac and renal failure and stroke, as well as retino- and nephropathy. ${ }^{2}$

In the last decades the prevalence of hypertension has increased and it is expected to do so further. ${ }^{3}$
Overall the global prevalence of hypertension was reported as $26.4 \%$ based upon studies in adult populations, ${ }^{4} 13.5 \%$ of the global total deaths were caused by hypertension-related diseases. ${ }^{5}$ By 2008 the prevalence was $30 \%$ and for about half of the hypertensive patients blood pressure (BP) was under control. ${ }^{6}$ By 2025 , the worldwide prevalence of hypertension is predicted to increase by $60 \%$ to a total of 1.56 billion. ${ }^{7}$ Despite the availability of a wide range of antihypertensive medications, about

Address of Correspondence: Prof. Mohammad Nazrul Islam, UGC Professor of Cardiology \& Course Director, Faculty of Medicine, Bangabandhu Sheikh Mujib Medical University (BSMMU), Dhaka, Bangladesh. Email: mnislam3512@gmail.com. 
$45.5 \%$ oftreated patients in the US fail to achieve a BP control target of less than $140 / 90 \mathrm{mmHg} .{ }^{3} \mathrm{In}$ European countries the number of patients not reaching BP control target varies from $59.7 \%$ in England to $81.3 \%$ in Spain, demonstrating substantial unmet need in the effective treatment of arterial hypertension. ${ }^{8}$

Compliance is significantly influenced by the number of pills a patient is prescribed to take. ${ }^{9}$ This 'pill burden' is further intensified by the high rate of comorbidities that often need treatment. Therefore, single-pill combination regimens have been developed. In addition to increased adherence, combination therapies can have beneficial effects on hypertension control when drugs with different mechanisms are combined. ${ }^{10}$ The combination of the calcium channel blocker amlodipine and the angiotensin II receptor blocker valsartan has shown to have an improved efficacy and safety profile compared with monotherapy. ${ }^{11,12}$

Hence, there is a strong rationale for exploration of real-life practices in hypertension treatment in this country and providing evidence for antihypertensive efficacy and tolerability for widely used medications by western populations in these regions. International hypertension guideline acknowledge that most patients will require two or more antihypertensive medications to achieve $\mathrm{BP}$ control, either as separate agents or in a single pill combination. One of the combinations recommended by the European Society of Hypertension (ESH)/European Society of Cardiology (ESC) guideline is the combination of a calcium channel blocker (CCB) and an angiotensin receptor blocker (ARB). As amlodipine is the most widely prescribed $\mathrm{CCB}$ and valsartan is one of the most prescribed ARBs, the present study was conducted to establish the clinical usefulness, including antihypertensive effectiveness, safety, and tolerability, of their free-dose combination in a real-life outpatient setting.

\section{Methods:}

This prospective, open-label, non-comparative observational, multicenter study was conducted from July 2013 to October 2014 in different hospitals in Bangladesh. The study population consisted with male and female outpatients, aged $\geq 18$ years with established diagnosis of hypertension, for whom the treating physician recommended treatment with single pill combination (SPC) of amlodipine and valsartan in adherence with the prescribing information and who provided the consent. The observational period was $26 \pm 8$ weeks which covered at least 3 examinations for each patient according to the routine in daily practice. In case of discontinuation or interruption of treatment, the reason had to be given. The assignment of the patient to the therapy was decided within the current practice and the medical indication, and was clearly separated from the decision to include the patient in the study. Patient demographic and baseline characteristic data were taken at study entry include age, weight and height, treatment for hypertension received in the 12 months prior to study entry. Information about the physical examination, performed according to physicians' routine practice, were documented in the source documentation at the study site. Significant findings that are presented prior to study entry was recorded as medical conditions in the study CRF. Significant findings made after the start of the study which met the definition of an adverse event (AE) was recorded as AEs in the study CRF. Data on blood pressure, heart rate, weight measured at study entry (V1) and at approximately week 4 (V2) and week $26 \pm 8$ weeks (V4) intervals and height measured at entry (V1) were collected. The mean of three sitting blood pressure values were recorded. Body weight was measured with the patient in street clothes and without shoes to be rounded up (if $\geq 0.5$ $\mathrm{kg})$ or down $(<0.5 \mathrm{~kg})$ to the nearest kilogram. Height was recorded in centimeters. The arm in which the highest sitting diastolic pressures was found was the arm used for all subsequent readings throughout the study and was done by the same staff member at the same time of day, using the same equipment, at every visit. Using a calibrated standard sphygmomanometer and appropriate size cuff, arterial blood pressure determinations was made in accordance with the 1988 AHA Committee Report ${ }^{12}$ on blood pressure determination with the arm supported at the level of the heart, systolic pressure were recorded when the initial sound was heard (Phase I of the Korotkoff sound); diastolic pressure was recorded at the disappearance of the sound (Phase V of the Korotkoff sound). The cuff was deflated at a rate not greater than $2 \mathrm{mmHg} /$ sec. At each study visit, after having the patient in a sitting position for five minutes, systolic/diastolic 
blood pressure was measured three times. The repeat measurements were made at one-to-two minute intervals. The mean of all three sitting measurements was decisive for the study specific procedures. No up or down rounding was allowed. Effectiveness, tolerability and compliance were assessed by the investigator at the end of study using a subjective evaluation scale. All AEs- including serious adverse events (SAEs) and safety endpoints (where relevant) was collected and was recorded in the study database, irrespective of causal association. Eligible patients were included in the study after they provided informed consent, and if they were incapable of doing so, they were included after such consent was provided by a legally acceptable representative of the patient. The primary effectiveness variable was the status effect of amlodipine/valsartan as monotherapy on change from baseline blood pressure after 26 weeks treatment. A two-sided t-test was used to assess the change from baseline blood pressure. A p-value less than 0.05 indicated that the mean change from Baseline in the treatment group was significantly different from zero. The magnitude of this change from Baseline was assessed by the mean of the estimated difference. Supportive analyses for the change from Baseline blood pressure was carried out using an analysis of covariance (ANCOVA) model.

\section{Results:}

The study enrolled 278 patients. Of these 236(84.9\%) patients completed the study while $42(15.1 \%)$ patients discontinued. The only reasons for discontinuation were lost to follow-up [42(15.1\%)]. Non-serious adverse events were reported in $19(6.8 \%)$ cases though treatment had been continued and finally completed to those patients. The mean age of patients was 49.74 ( \pm 13.27$)$ years, and majority $217(78.1 \%)$ were less than or equal to 60 years of age (Table I).

\section{Table-I}

Distribution of age of the study population ( $n=278)$.

\begin{tabular}{lcc}
\hline Age group & Frequency & Percentage \\
\hline$\leq 60$ years & 217 & 78.1 \\
$>60$ years & 61 & 21.9 \\
Total & 278 & 100.0 \\
Mean \pm SD & \multicolumn{2}{c}{$49.74( \pm 13.27)$} \\
\hline
\end{tabular}

*SD= Standard deviation; Range: $18-100$ years

During enrollment of the study majority patients were in the more than $140 \mathrm{mmHg}$ systolic BP group which was 205(73.7\%) patients which was gradually decreased to $101(36.3 \%)$ and $59(21.2 \%)$ at $2^{\text {nd }}$ and final visit respectively. The changes was statistically significant $(\mathrm{p}=<0.05)$. The proportion of patients in the group of more than $90 \mathrm{mmHg}$ diastolic BP was gradually decreasing from baseline to the final visit during the single pill combination of amlodinpine/valsartan which was 95(34.2\%) during enrollment followed by $42(15.1 \%)$ and $33(11.9 \%)$ patients in $2^{\text {nd }}$ visit and final visit respectively (Table II).

The mean systolic BP of the study population was $152.67( \pm 19.86)$ in the baseline study. However the mean rates were $138.62( \pm 14.07)$ and $132.95( \pm 11.86)$ at $2^{\text {nd }}$ and final visit respectively. The difference among the three means were calculated to see the level of significance and was found that it was statistically significant $(p=0.0001)$. The mean diastolic BP of the study population was 90.47( $\mathrm{g} \pm 11.01)$ during enrollment of the study. However the mean DBP was gradually decrease to $82.03( \pm 8.91)$ and $77.55( \pm 6.52)$ at $2^{\text {nd }}$ and final visit respectively. The difference among the three means were calculated to see the level of significance and was found that it was statistically significant ( $p=0.0001)$ (Table III).

Considering the diabetes mellitus (DM) patients the high SBP was gradually decreased from $74(77.9 \%)$ patients to $50(52.6 \%)$ patients during enrollment and final visit respectively. Again in diabetes mellitus (DM) patients the high $\mathrm{DBP}(>80$ $\mathrm{mmHg}$ ) was gradually decreased from $61(64.2 \%)$ patients to $29(30.5 \%)$ patients during enrollment and final visit respectively (Table IV).

The mean weight of the patients were measured and found $70.38( \pm 10.66) \mathrm{kg}, 70.80( \pm 12.38) \mathrm{kg}$ and $70.1160( \pm 12.29) \mathrm{kg}$ at baseline, $2^{\text {nd }}$ visit and final visit respectively $(p=0.814)$. The mean pulse of the patients were measured from baseline and found $78.35( \pm 9.29)$ beats/minute, $77.40( \pm 9.08)$ and $76.28( \pm 8.18)$ beats/minute at baseline, $2^{\text {nd }}$ visit and final respectively $(p=0.055)$. Oedema was absent in majority of the study population which was 271(97.5\%); however in the 2 nd visit and final visit the number was slightly decreased which was $254(97.7 \%)$ and 230(92.0\%) patients respectively. Among these 20 edema cases in final visit maximum were in mild form which was 19 cases and only 1 case was reported as moderate edema (Table V). 
Table-II

Changes of SBP according to the proportion of non-diabetic study population from baseline to final $\operatorname{visit}(n=278)$.

\begin{tabular}{lcccc}
\hline SBP $(\mathrm{mmHg})$ & Baseline & $2^{\text {nd }}$ & Final & $\mathrm{p}$ \\
& Visit & Visit & Visit & value \\
\hline SBP $(>140)$ & $205(73.7 \%)$ & $101(36.3 \%)$ & $59(21.2 \%)$ & $<0.05$ \\
DBP $(>90)$ & $95(34.2 \%)$ & $42(15.1 \%)$ & $33(11.9 \%)$ & $<0.05$ \\
\hline
\end{tabular}

Table-III

Changesof mean SBP and DBP from baseline in the patients during follow up visit (mean $\pm S D)$.

\begin{tabular}{lccccc}
\hline BP & Baseline Visit & $2^{\text {nd }}$ Visit & Final Visit & p value & F value \\
\hline SBP & $152.67( \pm 19.86)$ & $138.62( \pm 14.07)$ & $132.95( \pm 11.86)$ & 0.0001 & 110.037 \\
DBP & $90.47( \pm 11.01)$ & $82.03( \pm 8.91)$ & $77.55( \pm 6.52)$ & 0.0001 & 138.317 \\
\hline
\end{tabular}

Table-IV

Changes of SBP\& DBP according to the proportion of DM patients from baseline to final visit $(<130 / 80 \mathrm{~mm} \mathrm{Hg})$.

\begin{tabular}{lcccc}
\hline$(\mathrm{mmHg})$ & Baseline Visit & 2nd Visit & Final Visit & $\mathrm{p}$ value \\
\hline SBP $(>130)$ & $74(77.9 \%)$ & $50(52.6 \%)$ & $50(52.6 \%)$ & $<0.05$ \\
DBP $(>80)$ & $61(64.2 \%)$ & $29(30.5 \%)$ & $29(30.5 \%)$ & $<0.05$ \\
\hline
\end{tabular}

Table-V

Change from baseline in weight among the study population.

\begin{tabular}{lccccc}
\hline Variable & Baseline & $2^{\text {nd }}$ Visit & $3^{\text {rd }}$ Visit & $p$ value & F value \\
\hline Weight Mean $( \pm \mathrm{SD})$ & $70.38( \pm 10.66)$ & $70.80( \pm 12.38)$ & $70.12( \pm 12.29)$ & 0.814 & 0.206 \\
Pulse Mean $( \pm \mathrm{SD})$ & $78.35( \pm 9.29)$ & $77.40( \pm 9.08)$ & $76.28( \pm 8.18)$ & 0.055 & 2.907 \\
Oedema & $7(2.5 \%)$ & $6(2.3 \%)$ & $20(8.0 \%)$ & 0.0013 & \\
\hline
\end{tabular}

Good tolerability was reported in majority of the patients which were $187(71.6 \%)$ cases followed by very good and average which were $58(22.2 \%)$ patients and 16(6.1\%) patients respectively. Among the 278 patients no death was reported after taking the amlodipine/valsartan drug. Furthermore there was no severe adverse effect was reported. Oedema was the only reported non-serious adverse events which was $19(6.8 \%)$ cases. However the rash had not been reported in this study.

\section{Discussion:}

Hypertension is among the leading causes of death worldwide. ${ }^{3}$ Efficacy and safety profile of single pill combination (SPC) of amlodipine/valsartan demonstrated in randomized controlled trials, although critical, is not entirely reflected in daily clinical practice. ${ }^{4,7}$ Limited patient numbers determined by stringent inclusion and exclusion criteria of RCT preclude application of its findings to a larger population. Observational studies are needed to examine the effectiveness of a drug previously documented to be efficacious how a drug works in daily practice, under ordinary and variable conditions, prescribed by licensed clinicians with varying degrees of knowledge and expertise, to treat a variety of eligible patients. An advantage of observational studies is the access to a large, 
diverse groups of patients who better represent the population to which a drug is prescribed, and safety and effectiveness data collected from these studies are more valuable for clinical practices. This study was described an observational, multicenter, prospective, open-label study to assess effectiveness, safety and tolerability in patients with arterial hypertension receiving amlodipine/ valsartan in a real-world setting. It is expected that this study will elucidate the "real-world" determinants of clinical response to amlodipine/ valsartan and enable building an evidence-based approach to treatment, medical education, and clinical support; ultimately leading to improved patient outcomes.In addition, the study has been monitored a large number of patients from diverse ethnic populations and has been allowed to evaluate subgroups with different ethnicity and different risk factors in terms of effectiveness, safety and tolerability.

Hypertension is an independent risk factor for cardiovascular diseases and each reduction of either $20 \mathrm{mmHg}$ in systolic BP or $10 \mathrm{mmHg}$ in diastolic BP correlates with a two fold decrease in the likelihood of a fatal coronary event. ${ }^{13}$ To achieve the currently recommended BP goal of which is $140 / 90 \mathrm{mmHg}$ and lower for spe-cific patient populations, it is estimated that at least $25 \%$ of patients will require combination therapy. ${ }^{14,15}$ The combined use of two different classes of antihyper-tensive drugs enables targeting of distinct biological pathways, thus enhancing efficacy compared with monotherapy. In addition, side effects caused by one drug class may be negated by the actions of another drug class that elicits opposing physiological compensatory mechanisms, resulting in a more favorable tolerability profile. ${ }^{16-19}$

Among the five main classes of antihypertensive drugs, the combination of either an angiotensin converting enzyme inhibitor (ACEi) or an ARB, which both inhibit the renin-angiotensin system, a calcium channel blocker is the most commonly used double-drug regimen. ${ }^{20}$ Compared with separate tablets for each drug, fixed-dose combination (FDC) tablets are associ-ated with a higher rate of adherence to treatment, and, as a consequence, a greater proportion of patients attaining their $\mathrm{BP}$ goal over time. ${ }^{21,22}$
The management of hypertension is indeed a challenge especially in the elderly; high $\mathrm{BP}$ can occur in more than two thirds of individuals after the age of 65 years; and the elderly are known to be a population with low rates of BP control. ${ }^{23}$ Clinical trials conducted exclusively in the elderly are limited, leading to disparity in the recommendations for optimal BP control offered by various committees or societies. ${ }^{24}$

Major hypertension studies have shown that many patients with hypertension will require two or more antihypertensive drugs to achieve their BP goals, and addition of a further BP-lowering therapy particularly from another therapeutic class to an existing antihypertensive drug regimen is likely to deliver additional BP lowering and improved $\mathrm{BP}$ control. ${ }^{24}$ It has been reported that amlodipine/ valsartan have provided incremental BP reductions in patients receiving prior monotherapy. ${ }^{25}$ In addition, the reductions were consistent across different classes of prior antihypertensive monotherapy and dual combinations. The results observed were not dissimilar to those reported in previously conducted randomized clinical trials, such as the 16-week EX-FAST study where the amlodipine/valsartan combination delivered meaningful BP reductions in patients uncontrolled on antihypertensive monotherapy, including betablockers, CCB, ACEi, ARB and diuretics. ${ }^{26}$ The present study findings of $\mathrm{BP}$ reductions with an amlodipine/valsartan in patients previously treated with monotherapy are also similar to those reported in another large observational study in a real-life setting and conducted in Chinese patients. ${ }^{27}$ The results of the present study can be used in a generalized large and diverse group of patients suffering from hypertension to whom the drug is prescribed. The results of this study have demonstrated the effectiveness, safety and tolerability of amlodipine/valsartan in patients with hypertension in the general population in a real world settings.

\section{Acknowledgements:}

The authors acknowledge all investigators at the participating centers and all patients for their commitment to the study that was supported by Novartis (Bangladesh) Limited. Xplore Business Limited, Dhaka provided the medical writing support for the manuscript. All the authors 
participated in the development, reviewing and final approval of the manuscript and took full responsibility for the contents of the article. The study was funded by the Novartis (Bangladesh) Limited.

\section{References:}

1. Hajjar I, Kotchen JM, Kotchen TA. Hypertension: trends in prevalence, incidence, and control. Annu Rev Public Health 2006;27:465-490.

2. Whitworth JA, World Health Organization, International Society of Hypertension Writing Group. 2003 World Health Organization (WHO)/ International Society of Hypertension (ISH) statement on management of hypertension. J Hypertens 2003; 21: 1983-1992.

3. Egan BM, Zhao Y, Axon RN. US trends in prevalence, awareness, treatment, and control of hypertension, 1988-2008. JAMA 2010;303:2043-2050.

4. Kearney PM, et al.. Global burden of hypertension: analysis of worldwide data. Lancet 2005;365:217-223.

5. Lawes CM, Vander HS, Rodgers A. Global burden of blood-pressure-related disease, 2001. Lancet 2008;371:1513-1518.

6. Hagendorff A, Kurz I, Maller A, Klebs S. Evaluation of effectiveness and safety of amlodipine/valsartan/ hydrochlorothiazide single-pill combination therapy in hypertensive patients: an observational study. J Drug Assess 2014; 3:1-9.

7. Ferdinand KC, Nasser SA. A review of the efficacy and tolerability of combination amlodipine/valsartan in nonwhite patients with hypertension. American Journal of Cardiovascular Drugs 2013;13(5):301-313.

8. Wolf-Maier K, Cooper RS, Kramer H, et al.Hypertension treatment and control in fiveEuropean countries, Canada, and the United States. Hypertension 2004;43:10-17.

9. Mancia G, De Backer G, Dominiczak A, et al. Guidelines for the Management of Arterial Hypertension: The Task Force for the Management of Arterial Hypertension of the European Society of Hypertension (ESH) and of the European Society of Cardiology (ESC). J Hypertens 2007;25:1105-1187.

10. Mancia G, Laurent S, Agabiti-Rosei E, et al. Reappraisal of European guidelines on hypertension management: a European Society of Hyper-tension Task Force document. J Hypertens 2009;27:2121-2158.

11. da Silva PM. Efficacy of fixed-dose combination therapy in the treatment ofpatients with hypertension: focus on amlodipine/valsartan. Clin Drug Investig 2010;30:625-641.

12. AHA Committee Report on blood pressure determination (1988). Hypertension 1988; 1210A-1222A

13. Bramlage P, Fronk EM, Wolf WP, Smolnik R, Sutton G, Eschmieder R. Safety and effectiveness of a fixeddose combination of olmesartan, amlodipine, and hydrochlorothiazide in clinical practice. Vascular Health Risk Management 2015;11:1-8.
14. Mancia G, Laurent S, Agabiti-Rosei E, et al. Reappraisal of European guidelines on hypertension management: a European Society of Hypertension Task Force document. Blood Press 2009;18:308-347.

15. Gradman AH. Rationale for triple-combination therapy for manage-ment of high blood pressure. J Clin Hypertens 2010;12: 869-878.

16. Wright JT Jr, Dunn JK, Cutler JA, et al. Outcomes in hypertensive black and nonblack patients treated with chlorthalidone, amlodipine, and lisinopril. JAMA 2005;293:1595-1608.

17. Salahuddin A, Mushtaq M, Materson BJ. Combination therapy for hypertension 2013: an update. J Am SocHypertens 2013;7:401-407.

18. Kizilirmak P, Berktas M, Uresin Y, Yildiz OB. The efficacy and safety of triple vs dual combination of angiotensin II receptor blocker and calcium channel blocker and diuretic: a systematic review and metaanalysis. J Clin Hypertens 2013;15:193-200.

19. Neutel JM, Smith DH. Hypertension management: rationale for triple therapy based on mechanisms of action. Cardiovasc Ther 2013;31: 251-258.

20. Bramlage P, Hasford J. Blood pressure reduction, persistence and costs in the evaluation of antihypertensive drug treatment-a review. Cardiovas Diabetol 2009;8:18.

21. Panjabi S, Lacey M, Bancroft T, Cao F. Treatment adherence, clinical outcomes, and economics of tripledrug therapy in hypertensive patients. $J$ Am Soc Hypertens 2013;7:46-60.

22. Chobanian AV, Bakris GL, Black HR, et al. The Seventh Report of the JointNational Committee on Prevention,Detection, Evaluation, and Treatmentof High Blood Pressure: the JNC 7 report. JAMA. 2003;289: 2560-2572.

23. Weber MA, Schiffrin EL, White WB, et al. Clinical practice guidelinesfor the management of hypertension in the community: a statement bythe American Society of Hypertension and the International Society of Hypertension. J Clin Hypertens 2014;16:14-26.

24. Calhoun DA, Lacourciere Y, Crikelair N, Jia Y, Glazer RD. Effects of demographics on the antihypertensive efficacy of triple therapy with amlodipine, valsartan, and hydrochlorothiazide for moderate to severe hypertension. Curr Med Res Opin 2013;29:901-910.

25. Smith TR, Philipp T, Vaisse B, et al. Amlodipine and valsartan combinedand as monotherapy in stage 2 , elderly, and black hypertensive patients:subgroup analyses of 2 randomized, placebo-controlled studies. $J$ Clin Hypertens 2007;9:355-364.

26. Allemann Y, Fraile B, Lambert M, Barbier M, Ferber P, Izzo JL Jr.Efficacy of the combination of amlodipine and valsartan in patientswith hypertension uncontrolled with previous monotherapy: the Exforgein Failure after Single Therapy (EX-FAST) study. J Clin Hypertens 2008;10:185-194.

27. $\mathrm{Hu} \mathrm{D}$, Liu L, Li W. Efficacy and safety of valsartan/ amlodipine single pill Combination in 11,422 Chinese patients with hypertension: an observational study. Adv Ther 2014;31:762-775. 